\title{
Honey Improves Sperm Parameters in High Cholesterol Diet-Fed Male Rabbits
}

Zenab B. Hamad Mohamed ${ }^{1^{*}}$, Muhammad Bin Ibrahim ${ }^{1^{*}}$, Hamad Abdulsalam Hamad Alfarisi ${ }^{1}$, Azantee Yazmie Abdul Wahab $^{2}$, Azliana binti Abd Fuaat ${ }^{3}$ and Che Anuar Che Mohamad4

${ }^{1}$ Department of Nutrition Sciences, Kulliyyah of Allied Health Sciences, International Islamic University Malaysia, Kuantan, Pahang, Malaysia

${ }^{2}$ Department of Obstetrics and Gynaecology, Kulliyyah of Medicine, International Islamic University Malaysia, Kuantan, Pahang, Malaysia

${ }^{3}$ Department of Pathology \& Laboratory Medicine, International Islamic University Malaysia Medical Centre, Kuantan, Pahang, Malaysia

${ }^{4}$ Department of Basic Medical Sciences, Kulliyyah of Pharmacy, International Islamic University Malaysia, Kuantan, Pahang, Malaysia

\begin{abstract}
Overconsumption of a high-energy diet has a negative impact on sperm motility, morphology, vitality and concentration. Hence, this study aims to investigate the effects of honey on sperm parameters of high cholesterol diet-fed rabbits and compare its effects with atorvastatin. Forty-eight male New Zealand white rabbits were assigned into 6 groups: Control (C): commercial pellet; $\mathrm{CH}$ : commercial pellet and $600 \mathrm{mg} / \mathrm{kg} /$ day Trihoney; HCD: $1 \%$ cholesterol diet; DH1: $1 \%$ cholesterol diet and 300 $\mathrm{mg} / \mathrm{kg} /$ day Trihoney; DH2: $1 \%$ cholesterol diet and $600 \mathrm{mg} / \mathrm{kg} /$ day Trihoney; DAt: $1 \%$ cholesterol diet and $2 \mathrm{mg} / \mathrm{kg} /$ day atorvastatin. After 12 weeks, each rabbit was anaesthetized. Sperm were obtained from the cauda of the epididymis. Percentages of progressive (PM) and total motility (TM) were assessed using light microscope. Vitality and morphology were assessed using Eosin-Nigrosin stain. Sperm concentration was calculated using haemocytometer. Administration of $1 \%$ cholesterol diet reduced the percentages of PM, TM and normal sperm. Treatment with atorvastatin reduced the percentages of PM, TM, live and normal sperm. A marked reduction in sperm concentration was detected in the HCD and DAt groups. Trihoney groups expressed significantly higher percentages of PM, TM, normal sperm, live sperm and sperm concentration than the HCD and DAt groups. These results indicate that Trihoney has the potential to minimize the negative impacts of a high cholesterol diet on sperm parameters.
\end{abstract}

Keywords: high cholesterol diet; sperm parameters; Trihoney; atorvastatin

\section{INTRODUCTION}

Spermatogenesis is a multistep process through which sperm are produced from male germ cells in the seminiferous tubules of the testes. It is a sensitive process requiring optimal conditions to occur perfectly as it is essential for male reproduction (Azenabor et al., 2015). Poor semen quality is a widespread problem and it is one of the causes of infertility in approximately half the number of couples seeking assistance in order to achieve parenthood (Jensen et al., 2013). Sperm count, motility and morphology are parameters used to estimate male fertility (Wong et al., 2000). They provide information about the functions of the seminiferous tubules, epididymis, and accessory sex glands. They also give an idea about the diagnosis and prognosis of infertility (Esteves, 2014). Abnormal sperm analysis includes oligozoospermia (sperm count less than $39 \times 10^{6} /$ ejaculate or sperm concentration less than $15 \times 10^{6} / \mathrm{mL}$ ), asthenozoospermia

*Corresponding author's e-mail: abumaisarah@iium.edu.my, zenab.B.zoubi@gmail.com 
(progressive motility less than 32\%) and teratozoospermia (normal morphology less than 4\%) or a combination of any of these, in addition to several others (WHO, 2010). Overconsumption of a high energy diet has a negative impact on spermatogenesis at central and gonadal levels. It disrupts energy supply to male germ cells, induces sperm defects and spermatogenesis arrest (Rato et al., 2014). Hypercholesterolemia induced by a high cholesterol diet was found to reduce sperm functionality, count and motility coupled with an increase in sperm morphological abnormalities (Saez Lancellotti et al., 2010, 2013). Furthermore, it impairs spermatogenesis (Mohamed et al., 2020a) and markedly reduces epididymal mature sperm count (Mohamed et al., 2020b). Although extensive research has been conducted and abundant information are available about male infertility, the use of medical treatment is associated with various side effects (Dabaja \& Schlegel, 2014) and assisted reproductive technology is expensive and not always available and successful (Mora-Esteves \& Shin, 2013). The inclination of the general population nowadays is toward the use of herbal medicine (Zarei et al., 2014). Trihoney is a mixture of three types of honey namely Trigona, Mellifera and Tualang at a specific ratio. It is a product developed by the Department of Nutrition Sciences, Kulliyyah of Allied Health Sciences, International Islamic University Malaysia. It was optimized using Response Surface Methodology (RSM) of Design Expert Version 6.0 software. It has a high total phenolic content. Hence, the objective of the current study is to investigate the protective effects of Trihoney on sperm parameters of high cholesterol diet-fed male rabbits and compare its effects with atorvastatin, which is the most commonly used among statins that are the first line lipid lowering agents.

\section{MATERIALS AND METHOD}

\section{A. Ethics Statement}

The details of the current animal experiment were reviewed and approved by the International Islamic University Malaysia Institutional Animal Care and Use Committee (IACUC-IIUM), IIUM, Kuantan campus.

\section{B. Chemicals}

Atorvastatin (Atorvastatin Winthrop $\AA$, Prague-Czech), cholesterol powder (Nacalai-Tesque, Japan), cholesterol-free coconut oil (Certified Organic, Philippines), sperm washing media (modified HTF medium with human serum albumin $5.0 \mathrm{mg} / \mathrm{mL}$, Irvine Scientific, USA), VitalScreen kit (FertiPro, Belgium).

\section{Animals and Diets}

Forty-eight mature male New Zealand white rabbits with body weight of 2000-2500g were used in this study. They were housed in separate cages at a temperature of $15-21^{\circ} \mathrm{C}$ and humidity of $45-65 \%$ with 12 hours light/dark cycles. They had free access to water and pellet for an acclimatization period of 2 weeks. The rabbits were then randomly assigned into one of the six groups, with eight animals each as demonstrated in Table 1.

Table 1. Animal grouping of the current experiment

\begin{tabular}{|c|c|c|}
\hline Group & $\begin{array}{l}\text { Given } \\
\text { name }\end{array}$ & Diet and Treatment \\
\hline I & $\mathrm{C}$ & $\begin{array}{c}\text { Commercial rabbit pellet + } \\
\text { No treatment }\end{array}$ \\
\hline II & $\mathrm{CH}$ & $\begin{array}{l}\text { Commercial pellet }+600 \\
\mathrm{mg} / \mathrm{kg} / \text { day of Trihoney }\end{array}$ \\
\hline III & HCD & $\begin{array}{c}1 \% \text { cholesterol }+ \text { No } \\
\text { treatment }\end{array}$ \\
\hline IV & DAt & $\begin{array}{c}1 \% \text { cholesterol }+2 \mathrm{mg} / \mathrm{kg} / \text { day } \\
\text { atorvastatin }\end{array}$ \\
\hline V & DH1 & $\begin{array}{c}1 \% \text { cholesterol + } 300 \mathrm{mg} / \\
\text { kg/day of Trihoney }\end{array}$ \\
\hline VI & DH2 & $\begin{array}{c}1 \% \text { cholesterol + } 600 \\
\mathrm{mg} / \mathrm{kg} / \text { day of Trihoney }\end{array}$ \\
\hline
\end{tabular}

The high cholesterol diet was prepared according to Mohamed et al. (2020b). Trihoney doses were calculated according to Reagan-Shaw et al. (2007) by conversion of human equivalent dose, which is $0.1-0.2 \mathrm{~g} / \mathrm{Kg} / \mathrm{day}$ (Mohamed et. al., 2011; Natural Medicines Comprehensive Database, 2016), to animal equivalent dose. The used dose of atorvastatin was $2 \mathrm{mg} / \mathrm{kg} /$ day (Du et al., 2013). Atorvastatin was reconstituted in $1 \mathrm{~mL}$ of distilled water before its oral administration (Song et al., 2014). The duration of 
spermatogenesis in rabbits is between 7 to 8 weeks and the studies that aim to determine the effects of exogenous factors on spermatogenesis should be continued at least for 10 weeks (International Rabbit Reproduction Group, 2005), therefore this experiment was carried out for 12 weeks.

The purpose of having $\mathrm{CH}$ group was to evaluate the enhancing effect of Trihoney on sperm parameters of normocholesterolemic rabbits. It also investigates the safety of Trihoney to be consumed without negative impacts of Trihoney itself on the tested parameters.

\section{Preparation of Caudal Epididymal Sperm Suspension}

At the end of the 12 weeks, the rabbits fasted overnight and anaesthetized using intramuscular injection of ketamine/ xylazine at a dose of $50 / 10 \mathrm{mg} / \mathrm{kg}$ body weight (Zhao et al., 2013). A longitudinal midline incision was made through the abdominal cavity and pelvis. The right testis and epididymis were immediately and carefully excised and separated from each other. The sperm were obtained from the cauda of the excised right epididymis (Chen et. al., 2012; Yamamoto et al., 1999). The cauda was placed immediately into a sterile petri dish (Nalgene, Denmark) containing $4 \mathrm{~mL}$ of sperm washing media pre-warmed at $37^{\circ} \mathrm{C}$ (Yamamoto et. al., 1999; Ilbey et $a l .$, 2009). The cauda was minced and incubated in the prewarmed sperm washing media for 5 to 10 minutes to allow recovery and dispersion of sperm (Chen, Gong \& Xu, 2012; Rato et al., 2013).

\section{E. Analysis of Sperm Motility}

Ten microliters of sperm suspension were placed on a prewarmed slide $\left(37^{\circ} \mathrm{C}\right)$ and covered with a pre-warmed cover slip $\left(37^{\circ} \mathrm{C}\right)$ size $22 \mathrm{~mm} \times 22 \mathrm{~mm}$ (MENZEL-GLASER $\left.\AA\right)$, to provide a chamber with $20 \mu \mathrm{m}$ depth, and examined under $\times 400$ magnification of the microscope (Leica, Germany) (WHO, 2010). Ten random fields were assessed and the average value was used as an indicator of motility (Rato et al., 2013). The percentages of progressive motility, total motility and immotile sperm were assessed for each rabbit (WHO, 2010).

\section{F. Analysis of Sperm Vitality and Morphology}

Sperm vitality was assessed by means of the dye exclusion method using Eosin-Nigrosin staining technique according to the protocol of VitalScreen kit (FertiPro, Belgium). A total of 200 sperm were assessed under $\times 400$ and $\times 1000$ magnifications to determine the percentages of live and dead sperm. Live sperm were identified by their white or light pink heads; whereas, dead sperm have dark pink or red coloured heads (WHO, 2010; Chen, Gong \& Xu, 2012). Sperm morphology percentages were assessed from the same smears prepared for vitality analysis with assessment of 200 sperm under $\times 400$ and $\times 1000$ magnifications. The sperm were tested for head defects: large or small, tapered, pyriform, round, amorphous or double heads; neck and midpiece defects: asymmetrical insertion of the midpiece into the head, thick or irregular, bent or abnormally thin; tail defects: coiled, bent, short or double tails or any combination of these (Ping et. al., 2014; WHO, 2010).

\section{G. Analysis of Sperm Concentration}

Sperm concentration was calculated using haemocytometer (Neubauer-improved, Hirschmann, European Union). An aliquot of $50 \mu \mathrm{L}$ from the sperm suspension was diluted with distilled water in a sterile Eppendorf tube; two replicates were prepared. The dilution was performed based on the number of sperm which was seen in the preparation used for motility. If the sperm count per $\times 400$ magnification was more than 101, a dilution of 1:20 (50 $\mu \mathrm{L}: 950 \mu \mathrm{L}$ ) was used; for sperm count between 16-100, the dilution was 1:5 (50 $\mu \mathrm{L}: 200 \mu \mathrm{L})$; whereas, a dilution of 1:2 (50 $\mu \mathrm{L}: 50 \mu \mathrm{L})$ was used if the sperm count was below 15 (WHO, 2010). After mixing the samples well, $10 \mu \mathrm{L}$ from each replicate dilution was transferred into one of the two chambers of the haemocytometer which was kept horizontally in a humid chamber for 5 minutes to prevent drying. Two-hundred sperm were assessed in each replicate with assessment of the central grid (number 5) at first; if the count did not reach 200 sperm in the central grid, the counting was continued in the adjacent grids number 4 and number 6 . For the samples of low concentrations, the counting was continued in the rest of the grids and involved all nine grids in some rabbits (WHO, 2010). The equation 
used for calculation of the concentration is as follows (WHO, 2010):

$\mathrm{C}=(\mathrm{N} / \mathrm{n}) \times(1 / 20) \times$ dilution factor $\left(\right.$ sperm $\left.\times 10^{6} / \mathrm{mL}\right)$

where: $\mathrm{C}=$ Concentration, $\mathrm{N}=$ Total number of sperm in both chambers and $n=$ number of rows or grids examined for the replicates.

\section{H. Statistical Analysis}

Data were processed using the Statistical Package for the Social Sciences Version 21 (SPSS Inc., Chicago, Illinois, USA). They were expressed as means and standard deviations. Oneway analysis of variance test (ANOVA) was used for data analysis followed by a post hoc test to determine any significant differences between the means of the independent groups. Differences were considered to be statistically significant at $\mathrm{p}$ values less than 0.05 .

\section{RESULT AND DISCUSSION}

The deleterious effects of a high cholesterol diet and hypercholesterolemia on sperm function and quality has been studied and reported both in animal and human studies. In human, hypercholesterolemia independent of obesity was found to be negatively associated with sperm morphology and vitality (Schisterman et al., 2014). In animals, hypercholesterolemia caused reduction in the sperm count, motility and vitality associated with an increase in the sperm morphological abnormalities (Saez Lancellotti et. al., 2010, 2013; Ouvrier et al., 2011). However, for the first time, this study demonstrated that honey supplementation-using Trihoney-recovered almost all of the changes in sperm parameters induced by the high cholesterol diet.

The results of the effects of $1 \%$ cholesterol diet, Trihoney and atorvastatin on the different categories of sperm motility are summarized in Table 2.
Table 2. Effects of 1\% cholesterol diet, Trihoney and atorvastatin on percentages of sperm motility

\begin{tabular}{lccc}
\hline $\begin{array}{l}\text { Parameters } \\
\text { Groups }\end{array}$ & $\begin{array}{c}\text { PM } \\
\text { (\%) }\end{array}$ & $\begin{array}{c}\text { TM } \\
\text { (\%) }\end{array}$ & $\begin{array}{c}\text { Immotile } \\
\text { sperm (\%) }\end{array}$ \\
\hline C & $85.38 \pm 7.96^{\mathrm{a}}$ & $96.40 \pm 1.16^{\mathrm{a}}$ & $3.60 \pm 1.16^{\mathrm{a}}$ \\
CH & $82.72 \pm 15.49^{\mathrm{a}}$ & $95.73 \pm 4.05^{\mathrm{a}}$ & $4.27 \pm 4.05^{\mathrm{a}}$ \\
HCD & $15.88 \pm 12.23^{\mathrm{b}}$ & $60.42 \pm 30.69^{\mathrm{b}, \mathrm{c}}$ & $39.58 \pm 30.69^{\mathrm{b}, \mathrm{c}}$ \\
DAt & $42.36 \pm 40.47^{\mathrm{b}, \mathrm{c}}$ & $54.16 \pm 49.24^{\mathrm{b}}$ & $45.84 \pm 49.24^{\mathrm{b}}$ \\
DH1 & $58.32 \pm 34.32^{\mathrm{a}, \mathrm{c}}$ & $79.43 \pm 27.34^{\mathrm{a}, \mathrm{c}}$ & $20.56 \pm 27.34^{\mathrm{a}, \mathrm{c}}$ \\
& & & \\
DH2 & $75.20 \pm 20.44^{\mathrm{a}}$ & $94.20 \pm 3.26^{\mathrm{a}}$ & $5.80 \pm 3.26^{\mathrm{a}}$
\end{tabular}

Data were analysed using one-way analysis of variance. A Post Hoc test (LSD) was used to test the significant difference between the groups. Values are given as mean \pm standard deviation. ${ }^{a, b, c}$ Values not sharing a common superscript letter within the same column differ significantly at $\mathrm{p}<0.05$. PM: progressive motility; TM: total motility. C: commercial pellet; $\mathrm{CH}$ : commercial pellet plus $600 \mathrm{mg} / \mathrm{kg} /$ day Trihoney; HCD: $1 \%$ cholesterol diet; DH1: $1 \%$ cholesterol diet plus $300 \mathrm{mg} / \mathrm{kg} /$ day Trihoney; DH2: $1 \%$ cholesterol diet plus $600 \mathrm{mg} / \mathrm{kg} /$ day Trihoney; DAt: $1 \%$ cholesterol diet plus $2 \mathrm{mg} / \mathrm{kg} /$ day atorvastatin.

Motility is an important characteristic of fertile sperm. It is the most widely used indicator of sperm function as it reflects structural and functional competence of the sperm (Partyka et al., 2012). The extent of progressive motility is related to pregnancy rate (WHO, 2010). Only sperm moving in straight patterns succeed in the process of fertilization; whereas, those swim in tight circles are unable to pass through the utero-tubal junction (Amelar et al., 1980). In the present study, administration of a high cholesterol diet induced reduction in the percentages of progressive $(\mathrm{p}<0.05)$ and total motility $(\mathrm{p}<0.05)$ and increased the percentage of immotile sperm ( $\mathrm{p}<0.05)$ compared to the control group. In agreement with this study, Saez Lancellotti et al. (2010, 2013) and Yamamoto et al. (1999) reported the same effects of a hypercholesterolemic diet on sperm motility in rabbits. The negative impact of a high cholesterol diet on sperm motility was also reported in transgenic mice (Ouvrier et al., 2011).

Normal morphology is another important attribute of sperm and its evaluation is essential in sperm analysis. It provides clinical information about the potential fertility of semen sample (Partyka et al., 2012). The alteration of normal sperm morphology could be a sign of subfertility (Saez Lancellotti et al., 2010). Cholesterol intake promotes several changes in sperm cells (Saez Lancellotti et al., 2013). In the 
current study, a high cholesterol diet significantly decreased the percentage of sperm with normal morphology $(\mathrm{p}<0.05)$ and increased the percentage of sperm with abnormal morphology $(\mathrm{p}<0.05)$ as demonstrated in Table 3 and Figure 1. Similar results were reported by Saez Lancellotti et al. (2010, 2013). In those studies, the morphological abnormalities were in the form of folded head and presence of cytoplasmic droplets; however, the morphological alterations in the present study were mostly in the form of coiled or bent tail, bent neck and double tails. The morphological abnormalities which were reported in our study are in agreement in part with another study conducted by Shalaby (2004) to study the effect of $\alpha$-tocopherol and simvastatin on infertility in hypercholesterolemic rats. Ouvrier et al. (2011) demonstrated an increase in the percentage of broken cells with high cholesterol diet.

Table 3 also demonstrates the effects of $1 \%$ cholesterol diet on sperm concentration. Sperm concentration is used to measure the ability of the testes to produce an adequate number of sperm and the patency of the male reproductive tract. It is related to fertilization and pregnancy rate and is a predictor of pregnancy (WHO, 2010). In this study, administration of $1 \%$ cholesterol diet caused severe reductions in the sperm concentration $(\mathrm{p}<0.05)$. This result is in line with the results reported by Saez Lancellotti et al. (2013) and Shalaby (2004). However, Ouvrier et al. (2011) reported that there is no difference in epididymal sperm count after a high cholesterol diet administration, which was attributed to the normal testicular structure and function in that study.

Another essential parameter of potentially fertile semen sample is the viable sperm (Mart' 1 nez, 2004). The effects of $1 \%$ cholesterol diet on sperm vitality are given in Table 3 and Figure 1. Even though there was a reduction in the percentage of live sperm after a high cholesterol diet administration in the present study, it lacks the significant difference from the control. Similar results were obtained by Saez Lancellotti et al. (2013) upon administration of a high cholesterol diet to male rabbits. Contradicting results exhibiting a significant reduction in sperm vitality after a high cholesterol diet administration were reported in previous studies conducted on mice and rats, which was suggested to be due to the earlier effect of the high cholesterol diet on the epididymal tissue than its effect on the testicular tissue (Ouvrier et. al., 2011; Shalaby, 2004).

Table 3. Effects of $1 \%$ cholesterol diet, Trihoney and atorvastatin on percentages of sperm vitality, sperm morphology and sperm concentration

\begin{tabular}{|c|c|c|c|c|c|}
\hline $\begin{array}{c}\text { Parameters } \\
\text { Groups }\end{array}$ & $\begin{array}{c}\text { Live sperm } \\
\text { (\%) }\end{array}$ & $\begin{array}{c}\text { Dead sperm } \\
(\%)\end{array}$ & $\begin{array}{c}\text { Normal sperm } \\
\text { (\%) }\end{array}$ & $\begin{array}{c}\text { Abnormal sperm } \\
\text { (\%) }\end{array}$ & $\begin{array}{c}\text { Concentration } \\
\left(\operatorname{Sperm} \times 10^{6} / \mathrm{mL}\right)\end{array}$ \\
\hline $\mathbf{C}$ & $89.50 \pm 4.51^{\mathrm{a}}$ & $10.50 \pm 4.51^{\mathrm{a}}$ & $95.25 \pm 3.13^{\mathrm{a}}$ & $4.75^{ \pm 3.13^{\mathrm{a}}}$ & $85.93 \pm 44.21^{\mathrm{a}}$ \\
\hline $\mathbf{C H}$ & $89.67 \pm 3.53^{\mathrm{a}}$ & $10.33 \pm 3.53^{\mathrm{a}}$ & $92.08 \pm 8.07^{a}$ & $7.92 \pm 8.07^{\mathrm{a}}$ & $86.18 \pm 33.29^{a}$ \\
\hline HCD & $64.80 \pm 32.03^{\mathrm{a}, \mathrm{b}}$ & $35.20 \pm 32.03^{\mathrm{a}, \mathrm{b}}$ & $64.22 \pm 25.23^{b}$ & $35.78 \pm 25.23^{b}$ & $12.43^{ \pm 12.74^{b}}$ \\
\hline DAt & $55.00 \pm 44.85^{\mathrm{b}}$ & $45.00 \pm 44.85^{\mathrm{b}}$ & $63.60 \pm 39.89^{b}$ & $36.40 \pm 39.38^{b}$ & $18.94 \pm 24.23^{b}$ \\
\hline DH1 & $76.75 \pm 30.59^{\mathrm{a}, \mathrm{b}}$ & $23.25 \pm 30.59^{\mathrm{a}, \mathrm{b}}$ & $82.33^{ \pm 16.06^{a, b}}$ & $17.67 \pm 16.06^{a, b}$ & $37.71 \pm 43.59^{b}$ \\
\hline DH2 & $86.58 \pm 6.75^{a}$ & $13.42 \pm 6.75^{\mathrm{a}}$ & $91.00 \pm 4.87^{\mathrm{a}}$ & $9.00 \pm 4.87^{\mathrm{a}}$ & $45.46 \pm 18.90^{b}$ \\
\hline
\end{tabular}

Data were analysed using one-way analysis of variance (ANOVA). A Post Hoc test (LSD) was used to test the significant difference between the groups. Values are given as mean \pm standard deviation of mean. a,b Values not sharing a common superscript letter within the same column differ significantly at $\mathrm{p}<0.05$. C: commercial pellet; CH: commercial pellet plus $600 \mathrm{mg} / \mathrm{kg}$ /day Trihoney; HCD: 1\% cholesterol diet; DH1: 1\% cholesterol diet plus 300 mg/kg/day Trihoney; DH2: $1 \%$ cholesterol diet plus $600 \mathrm{mg} / \mathrm{kg} /$ day Trihoney; DAt: $1 \%$ cholesterol diet plus $2 \mathrm{mg} / \mathrm{kg} /$ day atorvastatin. 


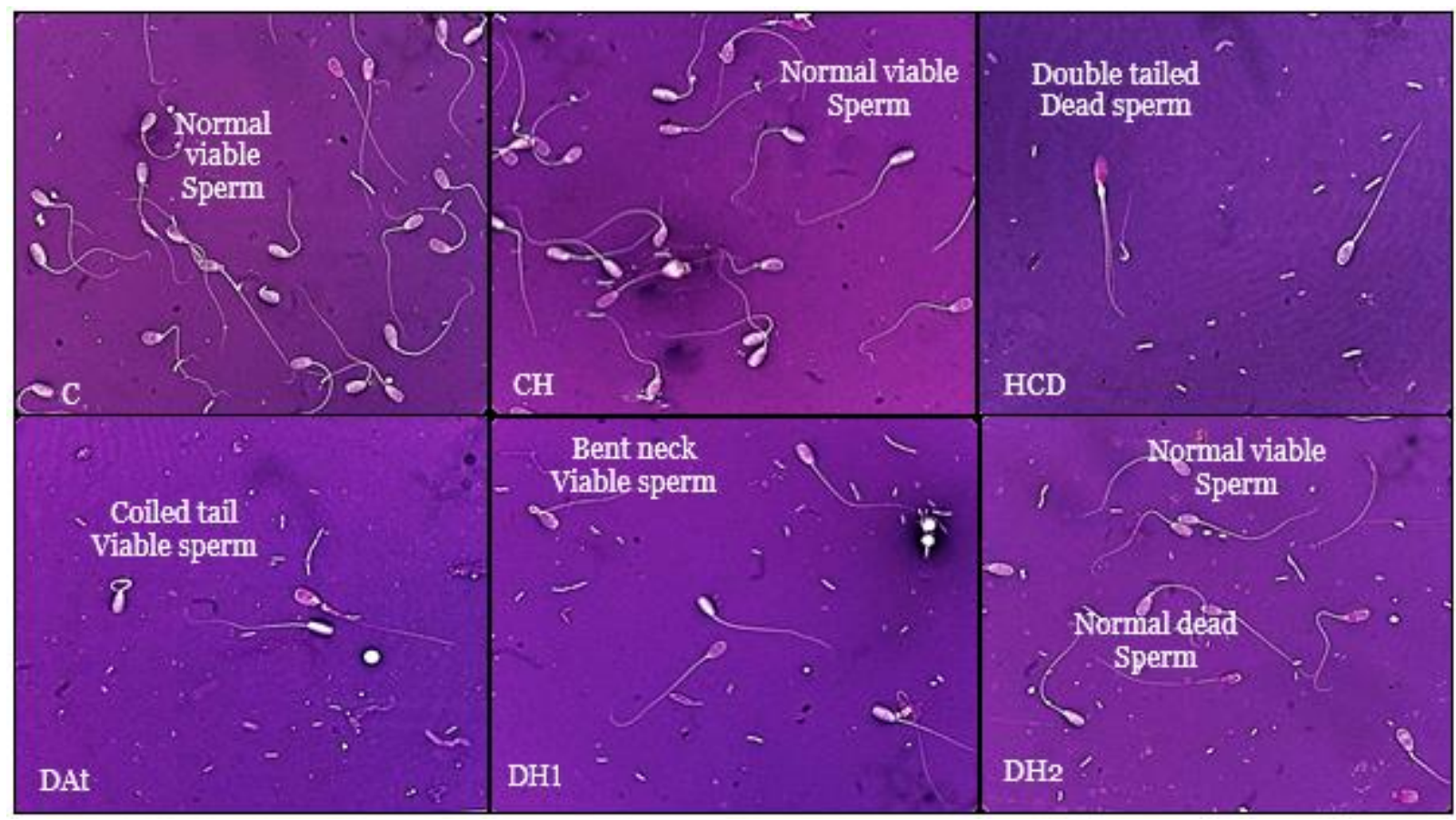

Figure 1. Eosin-Nigrosin stain of sperm morphology and vitality. The smears of the slides from the different groups were examined with $\times 1000$ magnification (oil lens). C: commercial pellet; $\mathrm{CH}$ : commercial pellet plus $600 \mathrm{mg} / \mathrm{kg} / \mathrm{day} \mathrm{Trihoney}$;

HCD: $1 \%$ cholesterol diet; DH1: $1 \%$ cholesterol diet plus $300 \mathrm{mg} / \mathrm{kg} /$ day Trihoney; DH2: $1 \%$ cholesterol diet plus 600 $\mathrm{mg} / \mathrm{kg} /$ day Trihoney; DAt: $1 \%$ cholesterol diet plus $2 \mathrm{mg} / \mathrm{kg} /$ day atorvastatin.

There was no significant difference between $\mathrm{CH}$ group and the control group in any of the tested sperm parameters. These comparable results indicate that Trihoney has no negative impacts on sperm parameters. It also showed that Trihoney has no enhancing effects on these tested parameters in the normocholesterolemic rabbits.

The deleterious impacts of a high cholesterol diet and hypercholesterolemia on sperm quality parameters could be induced via their negative impacts on testicular tissue. Hypercholesterolemia induces testicular degenerative changes that render seminiferous tubules atrophied and nonfunctioning with arrest of spermatogenesis (Mohamed et al., 2020a). These degenerative changes possibly caused by an oxidative stress damage (Ashrafi et. al., 2013; Shalaby, 2004). High cholesterol diet and hypercholesterolemia interrupt hypothalamic-pituitary-gonadal axis with a subsequent disruption of spermatogenesis (Hamad Mohamed et. al., 2020; Bashandy, 2007). The reduction in the sperm concentration and motility in a high cholesterol diet fedanimals may be attributed to the impairment of Sertoli and Leydig cells secretory function which subsequently affects spermatogenesis and epididymal sperm maturation. Epididymal dysfunction is another contributory factor in the reduction of sperm motility and cytostructural modifications that affect sperm morphology (Yamamoto et al., 1999). The epididymis was suggested as an early target of dietary cholesterol overload. The alteration induced by hypercholesterolemia in epididymal function causes a dramatic reduction of sperm motility and vitality and an increase in sperm morphological abnormalities (Ouvrier et al., 2011).

Concurrent supplementation of Trihoney with a high cholesterol diet improved the percentages of sperm progressive motility $(\mathrm{p}<0.05)$, total motility $(\mathrm{p}<0.05)$ and sperm with normal morphology $(\mathrm{p}<0.05)$ and reduced the percentages of immotile sperm $(\mathrm{p}<0.05)$ and sperm with abnormal morphology ( $\mathrm{p}<0.05$ ) when compared to the high cholesterol diet group; meanwhile, their levels were comparable to the control as illustrated in Tables 2 and 3 and Figure 1. More improvements were achieved by the Trihoney dose of $600 \mathrm{mg} / \mathrm{kg} /$ day than the dose of $300 \mathrm{mg} / \mathrm{kg} /$ day. Even though sperm concentration increased with Trihoney supplementation, it remained significantly lower than the control $(\mathrm{p}<0.05)$. To the best of our knowledge, no previous study has been conducted to determine the effects of honey against the changes in sperm parameters that are induced by 
a high cholesterol diet. However, there are numerous studies that have been conducted to determine the importance of honey in abating the impacts of other toxicants on sperm parameters. Administration of honey to rats exposed to cigarette smoke improved sperm count, percentage of motile sperm and the percentage of sperm with normal morphology (Mahaneem et al., 2011). Supplementation of honey to nicotine-treated male rats improved fertility through improvements in sperm concentration, percentage of motile sperm and the number of normal sperm (Aisyah et al., 2011). The same effects on sperm parameters were achieved by honey in rats fed with a high sucrose diet (Oyelowo et al., 2014) and in diabetic rats (Michael et al., 2015). Moreover, sperm progressive motility and post insemination pregnancy rate in mice were improved upon addition of $10 \%$ of honey to IVF media (Hadi, 2017). In human, honey supplementation to oligospermic men improved sperm concentration, motility and morphology (Ismail et al., 2014). Supplementation of $10 \%$ of honey to cryoprotectant solution results in an enhancement of sperm quality post-thawing (Fakhrildin \& Alsaadi, 2014).

The likely underlying mechanisms behind the positive effects of Trihoney on sperm parameters of high cholesterol diet-fed rabbits are its ability to maintain testicular integrity and optimize neuroendocrine gonadal axis and in turn enhancement of spermatogenesis, which were suggested to be due to Trihoney antioxidant activity as published recently (Hamad Mohamed et. al. 2020; Mohamed et al., 2020a). The antioxidant activity of honey reduces lipid peroxidation and restores the antioxidant system of the testicular tissue (Mohamed et al., 2011).

The other possible mechanisms could be via enhancement of spermiogenesis (Mohamed et al., 2012) and spermatogenesis through the decrease in testicular lactate dehydrogenase and increase in sorbitol dehydrogenase which are testicular marker enzymes for spermatogenesis (AbdulGhani et al., 2008). It possible that honey acts as a physiologic modulator of spermatogenic cells proliferation which influences the cell cycle of the seminiferous epithelium and increases spermatogenesis (Syazana et al., 2011). Furthermore, honey enhances spermatogenesis and sperm vitality via abating apoptosis and necrosis in testicular cells which could be due to the antioxidant properties of honey.
The antioxidant activity may neutralize the patterns of expression of apoptosis related genes and proteins or controlling anti-apoptotic patterns (Saki et al., 2013). Honey is a source of glucose, fructose, minerals and vitamins that stimulates sperm motility. Glucose and fructose are considered to be a fuel source for sperm motility (Hadi, 2017).

Treatment of the animals with atorvastatin showed better percentages of sperm PM and sperm concentration than using a high cholesterol diet alone; however, it did not reach the statistical significance. For percentages of sperm total motility, immotile sperm, vitality and normal morphology, atorvastatin treatment caused the worst results among the groups including the group that received high cholesterol diet alone. In a study carried out on healthy men, atorvastatin treatment resulted in a reduction of sperm concentration and vitality coupled with an increase in the percentage of abnormal sperm. Conversely, total sperm motility showed a significant improvement with no effects of atorvastatin observed on progressive motility (Pons-Rejraji et al., 2014). Use of atorvastatin in the treatment of hypercholesterolemic patients has been noticed as a cause of reduction of sperm motility. This was suggested to be due to the inhibition of coenzyme Q (10) (CoQ10) (Niederberger, 2005). Inhibition of cholesterol biosynthesis also inhibits the synthesis of CoQ10 as they share the same biosynthetic pathway. A brief exposure to atorvastatin causes a marked reduction of CoQ10 (Rundek et al., 2004). The negative impact of atorvastatin on sperm parameters could also be through reduction of serum and/or testicular testosterone. The reduction of serum and testicular testosterone with atorvastatin was reported both in animal and human studies (Hamad Mohamed et. al., 2020; Bustan \& Jawad, 2017; Kanat et al., 2009). Atorvastatin was suggested as one of the statins that might induce primary hypogonadism even at low doses (Corona et al., 2010). Statins reduce testosterone via reduction of cholesterol, inhibition of steps of steroidogenesis process or inhibition of de novo synthesis of cholesterol in Leydig cells (Schooling et al., 2013).

\section{CONCLUSION}

Trihoney showed its effectiveness as a potential protective natural product that minimizes the negative impacts of a high cholesterol diet on sperm quality parameters. The protective 
effects of Trihoney might be attributed to its high antioxidants constituents, which is suggested to be explored in future studies. On the other hand, treatment of rabbits with atorvastatin failed to reverse any of the changes induced by the high cholesterol diet in the sperm parameters.

\section{REFERENCES}

Abdul-Ghani, A-S, Dabdoub, N, Muhammad, R, AbdulGhani, R \& Qazzaz, M 2008, 'Effect of Palestinian honey on spermatogenesis in rats', Journal of Medicinal Food, vol. 11, no. 4, pp. 799-802.

Aisyah, H, Syazana, NS, Hashida, NH, Durriyyah Sharifah, HA \& Kamaruddin, MY 2011, 'Effects of nicotine and Gelam honey on testis parameters and sperm qualities of juvenile rats', Scientific Research and Essays, vol. 6, no. 26, pp. 5471-5474.

Amelar, RD, Dubin, L \& Schoenfeld, C 1980, 'Sperm motility', Fertility and Sterility, Elsevier Masson SAS, vol. 34, no. 3, pp. 197-215.

Ashrafi, H, Ghabili, K, Alihemmati, A, Jouyban, A, Shoja, MM, Aslanabadi, S, Adl, FH \& Hajhosseini, L 2013, 'The effect of quince leaf (Cydonia oblonga miller) decoction on testes in hypercholesterolemic rabbits: a pilot study', African Journal of Traditional, Complementary and Alternative Medicines, vol. 10, no. 2, pp. 277-282.

Azenabor, A, Ekun, AO \& Akinloye, O 2015, 'Impact of inflammation on male reproductive tract', Journal of Reproduction and Infertility, vol. 16, no. 3, pp. 123-129.

Bustan, A \& Jawad, A 2017, 'The effect of two types of statins (Rosuvastatin and Atorvastatin) on the fertility of male and female mice', British Journal of Medicine and Medical Research, vol. 19, no. 12, pp. 1-11.

Chen, X, Gong, L \& Xu, J 2012, 'Probiotics attenuate sperm damage induced by oxidative stress in rats', International Conference on Biomedical Engineering and Biotechnology, vol. 314, pp. 446-448.

Corona, G, Boddi, V, Balercia, G, Rastrelli, G, De Vita, G, Sforza, A, Forti, G, Mannucci, E \& Maggi, M 2010, 'The effect of statin therapy on testosterone levels in subjects consulting for erectile dysfunction', The Journal of Sexual Medicine, vol. 7, no. 4, pp. 1547-1556.

Du, B, Xu, G, Cao, H, Cui, W, Lin, S, Liu, Y \& Qin, L 2013, 'Effects of atorvastatin on expression of ICAM-1 in atherosclerotic rabbits', Journal of Cardiovascular Medicine, vol. 14, no. 2, pp. 120-126.

Esteves, SC 2014, 'Clinical relevance of routine semen analysis and controversies surrounding the 2010 World Health Organization criteria for semen examination', International Braz J Urol, vol. 40, no. 4, pp. 443-453.

Fakhrildin, MBM \& Alsaadi, RA 2014, 'Honey supplementation to semen-freezing medium improveshuman sperm parameters post-thawing', Journal of Family \& Reproductive Health, vol. 8, no. 1, pp. 27-31.

Hadi, IH 2017, 'Effect of honey on sperm characteristics and pregnancy rate mice', Bull. Iraq nat. Hist. Mus., vol. 14, no. 3, pp. 223-233.

Hamad Mohamed, ZB, M Brahim, HA Hamad Alfarisi, AY Abdul Wahab, A Abd Fuaat \& CA Che Mohamad 2020, 'Effect of trihoney (a mixture of trigona, mellifera and tualang) on male reproductive hormones and insulin resistance in hypercholesterolaemic rabbits', IMJM, vol. 19, no. 3, pp. 21-29.

Ilbey, YO, Ozbek, E, Simsek, A, Otunctemur, A, Cekmen, M \& Somay, A 2009, 'Potential chemoprotective effect of melatonin in cyclophosphamide- and cisplatin-induced testicular damage in rats', Fertility and Sterility, Elsevier Ltd, vol. 92, no. 3, pp. 1124-1132.

International Rabbit Reproduction Group 2005, 'Guidelines for the handling of rabbit bucks and semen', World Rabbit Sci, vol. 13, pp. 71-91.

Ismail, SB, Bakar, M, Nik Hussain, NH, Norhayati, MN, Sulaiman, SA, Jaafar, H, Draman, S, Ramli, R \& Wan Yusoff, WZ 2014, 'Comparison on the effects and safety of tualang honey and tribestan in sperm parameters, erectile function, and hormonal profiles among oligospermic males', Evidence-Based Complementary and Alternative Medicine, vol. 2014, pp. 1-10.

Jensen, TK, Heitmann, BL, Jensen, MB, Halldorsson, TI, Andersson, AM, Skakkebæk, NE, Joensen, UN, Lauritsen, 
MP, Christiansen, P, Dalgård, C \& Lassen, TH 2013, 'High dietary intake of saturated fat is associated with reduced semen quality among 701 young Danish men from the general population', American Journal of Clinical Nutrition, vol. 97, no. 2, pp. 411-418.

Kanat, M, Serin, E, Tunckale, A, Yildiz, O, Sahin, S, Bolayırlı, M, Arinc, H, Dirican, A, Karagoz, Y, Altuntas, Y \& Celebi, H 2009, 'A multi-center, open label, crossover designed prospective study evaluating the effects of lipid lowering treatment on steroid synthesis in patients with type 2 diabetes (MODEST Study)', Journal of Endocrinological Investigation, vol. 32, no. 10, pp. 852-856.

Mahaneem, M, Sulaiman, SA, Jaafar, H, Sirajudeen, KNS, Ismail, ZIM \& Islam, MN 2011, 'Effect of honey on testicular functions in rats exposed to cigarette smoke', Journal of ApiProduct and ApiMedical Science, vol. 3, no. 1, pp. 12-17.

Mart' inez, AIP 2004, 'Canine fresh and cryopreserved semen evaluation', Animal Reproduction Science, vol. 82-83, pp. 209-224.

Michael, MA, Balogun, AJ \& Adeniyi, MO 2015, 'Beneficial effects of honey-based diet on glycemic control and reproductive potential in diabetic rats', World Journal of Nutrition and Health, vol. 3, no. 2, pp. 41-46.

Mohamed, M, Sulaiman, SA, Jaafar, H \& Sirajudeen, KNS 2011, 'Antioxidant protective effect of honey in cigarette smoke-induced testicular damage in rats', International Journal of Molecular Sciences, vol. 12, no. 9, pp. 55085521.

Mohamed, M, Sulaiman, SA, Jaafar, H \& Sirajudeen, KNS 2012, 'Effect of different doses of Malaysian honey on reproductive parameters in adult male rats', Andrologia, vol. 44, pp. 182-186.

Mohamed, ZBH, Alfarisia, HAH, Wahabb, AYA, Abd Fuaatc, A, Mohamadd, CAC \& Ibrahime, MB 2020a, 'Trihoney improves testicular weight change and histopathological alterations in hypercholesterolemic rabbits', Asia Pacific Journal of Molecular Biology and Biotechnology, vol. 28, no. 3 , pp. $75-87$.

Mohamed, ZBH. Bin, IM, Alfarisi, HAH, Abdul Wahab, AY, Abd Fuaat, A \& Mohamad, CAC 2020b, 'Trihoney ameliorates hypercholesterolemia-induced epididymal histopathological changes in male rabbits', AsPac J. Mol. Biol. Biotechnol, vol. 28, no. 1, pp. 90-100.

Mora-Esteves, C \& Shin, D 2013, 'Nutrient supplementation: Improving male fertility fourfold', Seminars in Reproductive Medicine, vol. 31, no. 4, pp. 293-300.
Natural Medicines Comprehensive Database 2016, Therapeutic Research Faculty, publishers of Natural Medicines Comprehensive Database, Prescriber's Letter, and Pharmacist's Letter, California.

Niederberger, C 2005, 'Atorvastatin and male infertility: is there a link ?', Journal of Andrology, vol. 26, no. 1, pp. 12.

Ouvrier, A, Alves, G, Damon-Soubeyrand, C, Marceau, G, Cadet, R, Janny, L, Brugnon, F, Kocer, A, Pommier, A, Lobaccaro, JMA \& Drevet, JR 2011, 'Dietary cholesterolinduced post-testicular infertility', Plos one, vol. 6, no. 11, pp. 1-13.

Oyelowo, OT, Adekunbi, DA \& Dada, KA 2014, 'Protective role of Nigerian honey on sperm indices and testis in sucrose-fed rats', Bangladesh Journal of Medical Science, vol. 13 , no. 2, pp. 180-189.

Partyka, A, Niżański, W \& Ochota, M 2012, 'Methods of assessment of cryopreserved semen', in Current Frontiers in Cryobiology, In Tech open access publisher, pp. 547-574. Ping, NC, Hashim, NH \& Hasan Adli, DS 2014, 'Effects of Nigella sativa (Habbatus sauda) oil and nicotine chronic treatments on sperm parameters and testis histological features of rats', Evidence-based Complementary and Alternative Medicine, Hindawi Publishing Corporation, vol. 2014, pp. 1-7.

Pons-Rejraji, H, Brugnon, F, Sion, B, Maqdasy, S, Gouby, G, Pereira, B, Marceau, G, Gremeau, AS, Drevet, J, Grizard, G \& Janny, L 2014, 'Evaluation of atorvastatin efficacy and toxicity on spermatozoa, accessory glands and gonadal hormones of healthy men: a pilot prospective clinical trial', Reproductive Biology and Endocrinology, vol. 12, no. 1, pp. 65.

Rato, L, Alves, MG, Dias, TR, Lopes, G, Cavaco, JE, Socorro, S \& Oliveira, PF 2013, 'High-energy diets may induce a prediabetic state altering testicular glycolytic metabolic profile and male reproductive parameters', Andrology, vol. 1, no. 3, pp. 495-504.

Rato, L, Alves, MG, Cavaco, JE \& Oliveira, PF 2014, 'Highenergy diets: a threat for male fertility?', Obesity Reviews, vol. 15 , no. 12, pp. 996-1007.

Reagan-Shaw, S, Nihal, M \& Ahmad, N 2007, 'Dose translation from animal to human studies revisited', The FASEB Journal, vol. 22, no.3, pp. 659-661.

Rundek, T, Naini, A, Sacco, R, Coates, K \& DiMauro, S 2004, 'Atorvastatin decreases the coenzyme Q10 level in the blood of patients at risk for cardiovascular disease and stroke', Archives of Neurology, vol. 61, no. 6, pp. 889-892. 
Saez Lancellotti, TE, Boarelli, PV, Monclus, MA, Cabrillana, ME, Clementi, MA, Espínola, LS, Barría, JLC, Vincenti, AE, Santi, AG \& Fornés, MW 2010, 'Hypercholesterolemia impaired sperm functionality in rabbits', PLoS ONE, Edited by C, Combs, vol. 5, no. 10, pp. e13457.

Saez Lancellotti, TE, Boarelli, PV, Romero, AA, Funes, AK, Cid-Barria, M, Cabrillana, ME, Monclus, MA, Simón, L, Vicenti, AE \& Fornés, MW 2013, 'Semen quality and sperm function loss by hypercholesterolemic diet was recovered by addition of olive oil to diet in rabbit', PLoS ONE, vol. 8, no. 1: e52386, pp. 1-8.

Saki, G, Rajabzadeh, A, Khodadadi, A \& Sarkaki, A 2013, 'The effects of honey and vitamin $\mathrm{E}$ administration on apoptosis in testes of rat exposed to noise stress', Journal of Human Reproductive Sciences, vol. 6, no. 1, pp. 54-58.

Samir Bashandy, A 2007, 'Effect of fixed oil of nigella sativa on male fertility in normal and hyperlipidemic rats', International Journal of Pharmacology, vol. 3, no. 1, pp. 2733 .

Schisterman, EF, Mumford, SL, Chen, Z, Browne, RW, Boyd Barr, D, Kim, S \& Buck Louis, GM 2014, 'Lipid concentrations and semen quality: the life study', Andrology, vol. 2, no. 3, pp. 408-415.

Schooling, CM, Yeung, SLA, Freeman, G \& Cowling, BJ 2013, 'The effect of statins on testosterone in men and women, a systematic review and meta-analysis of randomized controlled trials', BMC Medicine, vol. 11, no. 57, pp. 1-9.

Shalaby, M 2004, 'Effect of alpha-tocopherol and simvastatin on male fertility in hypercholesterolemic rats', Pharmacological Research, vol. 50, no. 2, pp. 137-142.

Song, X, Liu, H, Wang, X, Li, Z \& Huang, C 2014, 'Atorvastatin combined with poly-unsaturated fatty acid confers better improvement of dyslipidemia and endothelium function', Lipids in Health and Disease, vol. 13, no. 186, pp. 1-5.

Syazana, NS, Hashida, NH, Majid, AM, Durriyah Sharifah, HA \& Kamaruddin, MY 2011, 'Effects of Gelam honey on sperm quality and testis of rat', Sains Malaysiana, vol. 40, no. 11 , pp. $1243-1246$.

WHO 2010, WHO laboratory manual for the Examination and processing of human semen, $5^{\text {th }}$ edn, WHO Press, Geneva, Switzerland.

Wong, WY, Thomas, CM, Merkus, JM, Zielhuis, GA \& Steegers-Theunissen, RP 2000, 'Male factor subfertility: possible causes and the impact of nutritional factors', Fertility and Sterility, vol. 73, no. 3, pp. 435-442.

Yamamoto, Y, Shimamoto, K, Sofikitis, N \& Miyagawa, I 1999, 'Effects of hypercholesterolaemia on Leydig and
Sertoli cell secretory function and the overall sperm fertilizing capacity in the rabbit', Human Reproduction, vol. 14, no. 6, pp. 1516-1521.

Zarei, A, Changizi-Ashtiyani, S, Rezaei, A, Sheidaee, H \& Nabiyoni, F 2014, 'The effect of chelidonium majus extract on the lipid profile and activity of pituitary-gonadal axis in hypercholesterolemic rats', Zahedan Journal of Research in Medical Sciences, vol. 16, no. 10, pp. 18-22.

Zhao, X-H, Qiu, JH, Cai, WQ, Li, S \& Li, W 2013, 'Preparation of infertile male rabbits by local electron beam irradiation for intratesticular transplantation of autologous bone marrow stem cells', Acta Cirurgica Brasileira, vol. 28, no. 2, pp. 148-153. 